Check for updates

London, UK

Cite this as: BMJ 2022;376:0212 http://dx.doi.org/10.1136/bmj.0212 Published: 01 February 2022

\section{From GP to government adviser: Karen Gully}

\section{The clinical director talks to Helen Jones about her varied career which includes advisory roles with the Welsh government}

\section{Helen Jones}

"Here comes the enemy" is something Karen Gully, professional adviser to the Strategic Programme for Primary Care in Wales and adviser to the post-covid recovery programme at Aneurin Bevan University Health Board, distinctly remembers hearing as she walked into a session with a group of GPs.

Speaking about her move from general practice into a health authority role, she recalls, "It was a bit of joke, but there was a sense that I had moved to the 'dark side.'

"We all agreed, however, that there were frustrations about the way systems worked around clinical practice and that someone should do something about them. I realised that was me."

Gully began her career in obstetrics and gynaecology before moving into general practice, where her own role model was her GP trainer, Adrian Eyre. "The whole team was engaged in teaching and individual interests were always encouraged. Adrian created a culture of openness and mutual support within the practice. He taught me so much."

She found herself first drawn to population health as a medical student in Bristol. "The community medicine module was a real eye opener on the wider determinants of health. Many outcomes are so heavily influenced by what happens long before your patient comes to see you and that intrigued me."

She became a GP partner and went on to undertake training in public health before being approached about a role as a medical director. "I was looking for a balance between the absolute immediacy of primary care and the slow pace of public health. The medical director role allowed me to work closely with primary and community care, but also to influence the wider system."

She admits to finding it difficult to say goodbye to patients with whom she had formed a bond. "It was hard to let that go," she says. "I also missed the immediacy of general practice, working with the team and the peer support and the camaraderie-when it works well, there is nothing else like it."

After a stint as a medical director, an opportunity arose with the Welsh government as a senior medical officer. "It came at the time of yet another NHS restructure, so I thought it was a good time to try it," she says.

"I found government policy colleagues to be incredibly bright and challenging. They were keen to understand what being patient facing felt like and to know what could work in practice. They then translated that into making the mechanics of government work. There were frustrations at times, of course, but that comes with most jobs."

Gully has no regrets about any career moves. "It's been fascinating to see the system from so many angles," she says. "I've had the privilege of working clinically, on government policy development, and in different managerial jobs but the purpose of every role was to help to improve care and to make systems better for our clinical colleagues."

And what has guided her career? "It would be lovely to be able to say that I had planned my career this way, but I certainly didn't. I was open to opportunities and willing to give things a try. It's about trusting your gut instinct-if the next job feels right then it probably is - and there will always be other opportunities ahead. So many younger colleagues have amazing transferable skills and talents, if only they knew it.”

\section{Nominated by Clifford Jones}

For quite some time now, Karen Gully has been a mentor, adviser, and role model.

She has done it all-been a GP, a medical director (twice), a senior medical officer with the Welsh government, and now a clinical director working on integration and developing cluster working.

Gully is an example of a clinical manager who wants to make an impact on outcomes. She has a quiet, collaborative style, but there is no doubting her experience and knowledge.

I now have the privilege of working with her as a peer. Although significantly more experienced than many of her colleagues, she makes a point of seeking and valuing the opinions of others.

I've been a grateful recipient of her ability to develop and encourage those around her. She is about to retire but still doing what she does best-bringing people together and getting the best out of those around her.

Clifford Jones is primary care clinical director, quality improvement and clinical innovation, at Aneurin Bevan University Health Board.

To nominate someone who has been a role model during your medical career, send their name, job title, and the reason for your nomination to awaters@bmi.com. 